\title{
Ground deformation mechanism due to deep excavation in sand: 3D numerical modelling
}

\author{
Dildar Ali Mangnejo ${ }^{1}$, Saeed Ahmed Soomro ${ }^{2}$, Naeem Mangi ${ }^{3}$ \\ ${ }^{1}$ Department of Civil Engineering, \\ Quaid-e-Awam University of Engineering, Science \& Technology, Nawabshah, Pakistan. \\ 1'dildarali72@gmail.com, ${ }^{2}$ soomrosaeedahmed99@ gmail.com, ${ }^{3}$ naeem08ce30@ gmail.com
}

\begin{abstract}
In densely built areas, development of underground transportation system often involves excavations for basement construction and cut-and-cover tunnels which are sometimes inevitable to be constructed adjacent to existing structure. Inadequate support systems have always been major concern as excessive ground movement induced during excavation could damage to neighbouring structure. A detailed parametric analysis of the ground deformation mechanism due to excavation with different depths in sand with different densities $\left(D_{r}=30 \%, 50 \%, 70 \%\right.$ and $\left.90 \%\right)$ is presented. 3D finite element analyses were carried out using a hypoplastic model, which considers strain-dependent and path-dependent soil stiffness. The computed results have revealed that the maximum settlement decreased substantially when the excavation is carried out in the sand with higher relative density. This is because of reason that sand with higher relative density possesses higher stiffness. Moreover, the depth of the maximum settlement of the wall decreases as the sand become denser. The ground movement flow is towards excavation in retained side of the excavation. On the other hand the soil heave was induced below the formation level at excavation side. The maximum strain level of $2.4 \%$ was induced around the diaphragm wall.
\end{abstract}

Key words : Deep excavation, Relative density of sand, Parametric study

\section{INTRODUCTION}

Due to shortage of lands, high-rise buildings are preferred to meet the development and economic growth in major cities [15]. Owing to the inherent lack of surface space in congested urban areas, deep excavation for basements and cut-and-cover tunnels are inevitably constructed adjacent to existing structures [14]. Buildings in nearby areas are present at a closed distance from the excavation. Excavation may induce unfavourable ground deformations that can affect adjacent structures. The excavation induced ground movement must carefully be monitored and controlled within an acceptable amount, to avoid potential damage to nearby structures. The failure of an excavation may have catastrophic consequences, and special care must be taken to avoid such failure. Prediction of excavation-induced ground movements is an essential part in the design of deep excavation, because of their possible adverse effects on nearby structures and other existing facilities. Particularly two-dimensional finite element method is used by researchers and practitioners due to its relative simplicity, flexibility and availability of computational facilities to simulate different field conditions and excavation techniques [8-12]. On most occasions, two-dimensional numerical model predicts the deformation and stress conservatively. However, this conservative prediction by numerical simulation for deep excavation depends on the efficiency of constitutive laws to represent few critical features of soil model e.g. estimation of soil parameters, location and nature of fictitious boundary conditions, effect of surcharge from existing structures, sequence and schedule of excavations, etc. Nonetheless, many researchers have studied these aspects [13-17]. Dinakar and Prasad [3] studied the performance of diaphragm wall on the stress distribution and deformation characteristics of ground below adjacent structure at vulnerable locations. A typical building load is idealised and its effects on excavation and supporting system is analysed in terms of bending moment, shear force and displacement of diaphragm wall. Results of the study revealed that diaphragm wall method of excavation was able to limit ground movements under buildings considerably and the excavation could be carried out safely. Hsiung et al. [12] modelled deep excavation in Taiwan with 3D finite element modelling. In their studies, diaphragm wall were modelled with plate elements. The study emphasised the corner effect, and the results corresponded well with the measured lateral wall deformation. Hsieh et al. [9] studied the effect of buttress walls in reducing deformation of the diaphragm walls in two case studies in Taipei. In absence of wall, the soil fails at very shallow depth. It was observed that for $20.0 \mathrm{~m}$ depth of excavation with diaphragm wall, the wall movements should be restricted within $0.1-0.3 \%$ of depth of excavation. Horizontal and vertical displacements as well as shear stress in soil decrease linearly with increase in distance of the structure from the excavation. Therefore, the minimum distance of excavation from existing structure could be estimated based on allowable stresses and displacement of ground. Korff et al. [20] proposed an analytical method to investigate reduction of capacity and increase in settlement of a nearby pile during 
excavation. It was reported that pile settlement due to excavation depends on the percentages of end bearing and shaft friction of the pile, the soil movement pattern, and the distribution of the maximum shaft friction with depth. It is well recognised that the stress-strain relationship of soils is highly nonlinear even at very small strain. The stiffness of most soils decreases as strain increases and depends on the recent stress or strain history of the soil [1,2]. Owing to non-linear soil behaviour, an excavation can cause reduction in the stiffness of the ground. To obtain a satisfactory numerical model of single pile responses to excavation-induced stress relief, the analysis needs to take account of the small strain non-linearity of soil.

\section{THREE-DIMENSIONAL FINITE ELEMENT ANALYSIS}

To investigate the ground deformation and diaphragm wall deflection mechanism due to multipropped excavation with different depths in sand with different relative densities $\left(D_{r}=30 \%, 50 \%, 70 \%\right.$ and $\left.90 \%\right)$, three-dimensional parametric study was conducted. The final depth of the excavation $\left(H_{e}\right)$ was taken as $25 \mathrm{~m}$. The excavation was performed in different stages (i.e. $\mathrm{h}=2,5,8,11,14,17,20,23$ and $25 \mathrm{~m}$ ) to investigate the different excavation depths.

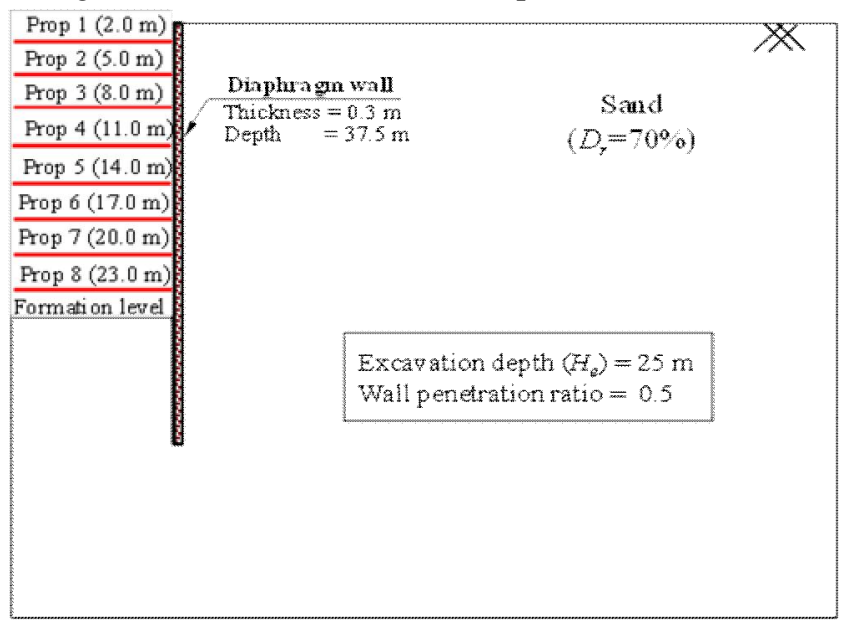

(a)

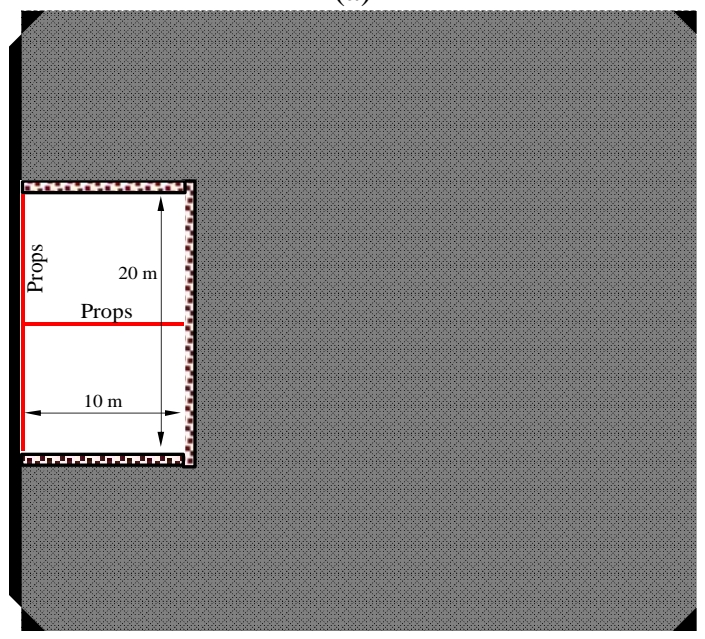

(b)

Figure 1: Configuration of a typical numerical run representing case $D_{r}=70 \%$ (a) elevation view (b) plan view
Four different relative densities of $D_{r}=30 \%, 50 \%, 70 \%$ and $90 \%$ of sand were adopted to investigate the relative density effects on ground deformation. Fig.1 (a) shows the elevation view the geometry of the excavation in sand with relative density of $70 \%$. The excavation was supported by $0.3 \mathrm{~m}$ thick diaphragm wall. The ratio of wall penetration depth to excavation depth is typically $0.5-2$ in engineering practice [11] and thus a value of 0.5 is adopted in this study. The props are used to support the diaphragm wall with a vertical spacing of 3 $\mathrm{m}$. The props are modelled as soft with axial rigidity of $81 \times$ $10^{3} \mathrm{kNm}$ [12]. Fig.1 (b) illustrates the plan view of the configuration of the numerical simulation. The length of the excavation is $20 \mathrm{~m}$. Due to symmetry, only half of the excavation was simulated. A monitoring section was selected at the transverse centreline of the excavation.

\subsection{Finite element mesh and boundary conditions}

Fig. 2 shows an isometric view of a finite element mesh used for analysing the excavation problem. The size of the mesh for each numerical runs is $50 \mathrm{~m} \times 20 \mathrm{~m} \times 40 \mathrm{~m}$. These dimensions were sufficiently large to minimise boundary effects in the numerical simulation as further increment in the dimensions of the finite element mesh did not lead to any change in the computed results. Regarding the element size in the mesh, it is found that further halving the adopted mesh size only leads to a change of computed results of no more than $0.2 \%$, suggesting the mesh is sufficiently fine. Eight-noded hexahedral brick elements were used to model the soil, the pile and the diaphragm wall, while two-noded truss elements were adopted to model the props. Roller and pin supports were applied to the vertical sides and the base of the mesh, respectively. Therefore, movements normal to the vertical boundaries and in all directions of the base were restrained. The wall-soil interface was modelled as zero thickness by using duplicate nodes.

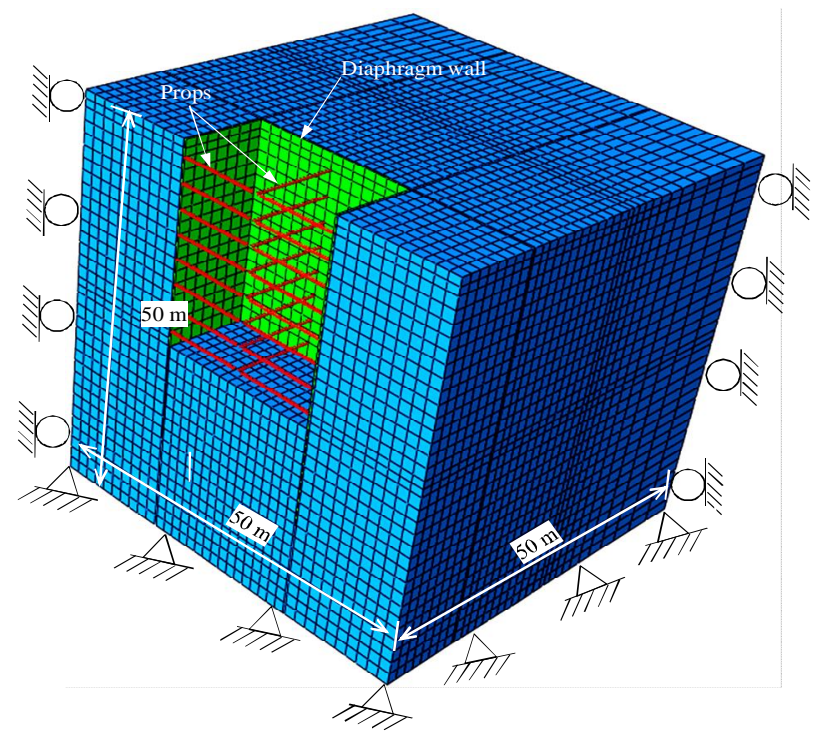

Figure 2: Finite element mesh and boundary conditions of a typical numerical analysis (i.e. $D_{r}=70 \%$ )

The interface was modelled by the Coulomb friction law, in which the interface friction coefficient $(\mu)$ and limiting 
displacement $\left(\gamma_{\text {lim }}\right)$ are required as input parameters. A limiting shear displacement of $5 \mathrm{~mm}$ was assumed to achieve full mobilization of the interface friction equal to $\mu \times p^{\prime}$, where $\mathrm{p}^{\prime}$ is the normal effective stress between two contact surfaces. The excavation process was simulated by deactivating soil elements inside excavation zone. In the meantime, the truss elements representing the props were activated.

\subsection{Constitutive model and model parameters used in finite element analysis}

Since the stress-strain relationship of soils is highly nonlinear even at very small strain and the stiffness of soil depends on the recent stress or strain history of the soil [1, 17], an advanced hypoplastic model was used to simulate the behaviour of sand in this study. The hypoplastic model was developed to describe non-linear response of granular material $[17,18,29]$. It consists of eight model parameters $\left(\phi^{\prime} \mathrm{c}, \mathrm{h}_{\mathrm{s}}, \mathrm{n}\right.$, $\mathrm{e}_{\mathrm{d} 0}, \mathrm{e}_{\mathrm{c} 0}, \mathrm{e}_{\mathrm{i} 0}, \alpha$ and $\left.\beta\right)$. The first six parameters $\left(\phi_{\mathrm{c}}^{\prime}, \mathrm{h}_{\mathrm{s}}, \mathrm{n}, \mathrm{ed}_{0}, \mathrm{ec}_{0}\right.$, $\mathrm{ei}_{0}$ ) of Toyoura sand were calibrated by Herle and Gudehus [6].The remaining two parameters ( $\alpha$ and $\beta$ ) were obtained by curving fitting Maeda and Miura [22]'s triaxial test results (at large strains).To account for strain-dependency and path-dependency of soil stiffness (at small strains), Niemunis and Herle [23] further improved the hypoplastic model by incorporating intergranular strain concept into the model. Five additional parameters $(\mathrm{mR}, \mathrm{mT}, \mathrm{R}, \beta \mathrm{r}$ and $\chi)$ are required. These five parameters were obtained by curve fitting stiffness degradation curves of Toyoura sand measured in this study. The measured and computed stiffness results show a reasonable agreement in both trend and magnitude with maximum difference being $10 \%$. The good match of computed results (with calibrated parameters) with that of the measured implies the capability of the

Table 1: Hypoplastic model parameters of sand adopted in this study

\begin{tabular}{lc}
\hline \multicolumn{1}{c}{ Description } & Parameter \\
\hline $\begin{array}{l}\text { Effective angle of shearing resistance at } \\
\text { critical state: } \phi\end{array}$ & $31 \mathrm{o}$ \\
Coefficient of at-rest earth pressure, Ko & 0.5 \\
Hardness of granulates, hs & $2.6 \mathrm{GPa}$ \\
Exponent, n & 0.27 \\
Minimum void ratio at zero pressure, edo & 0.61 \\
Maximum void ratio at zero pressure, eio & 1.10 \\
Critical void ratio at zero pressure, eco & 0.98 \\
Exponent $\alpha$ & 0.14 \\
Exponent $\beta$ & 6 \\
Parameter controlling initial shear modulus & 11 \\
upon $180^{\circ}$ strain path reversal, mR & \\
Parameter controlling initial shear modulus & 6 \\
upon90 strain path reversal, m & \\
Size of elastic range, $\mathrm{R}$ & $2 \times 10-5$ \\
Parameter controlling degradation rate of & 0.1 \\
stiffness with strain, $\beta \mathrm{r}$ & \\
Parameter controlling degradation rate of & 1.0 \\
stiffness with strain, $\chi$ & \\
\hline
\end{tabular}

Hypoplastic model (sand) to capture the small strain stiffness and degradation of the soil stiffness with strain, which is an important aspect of soil behavior to predict the soil movement during excavation $[1,3]$. The coefficient of at-rest earth pressure $(\mathrm{K} 0=0.5)$ was estimated based on effective angle of shearing resistance at critical state $\left(\phi^{\prime}=31 \mathrm{o}\right.$, as reported by Ishihara[18]) and Jáky [19]'s equation $\left(K_{e}=1 \quad \sin \varphi^{\prime}\right)$

Table1summarizes model parameters of Toyoura sand adopted in the numerical analyses. The diaphragm wall and the props were assumed to be linear elastic with Young's modulus of 35 $\mathrm{GPa}$ and Poisson's ratio of 0.25 . The unit weight of concrete was assumed to be $24 \mathrm{kN} / \mathrm{m}^{3}$.

\subsection{Numerical modeling procedure}

The numerical analysis modelling procedure for a typical case is summarized as follows:

a) Step 1: Set up the initial boundary and initial effective stress conditions (i.e., static effective stress conditions with varying $\mathrm{K} 0=0.50$ ).

b) Step2: Activate the brick elements representing single pile (modelled as "wished-in-place").

c) Step 3: Apply the working load (determined from numerical pile load test) on the pile.

d) Step 4: Allow excess pore pressure, which generated in result of application of working load on the pile, to dissipate.

e) Step 5: Activate the brick elements representing the diaphragm wall.

f) Step 6: Staged multi-propped excavation is simulated as described in section 2.1. After excavating to $3 \mathrm{~m}$ depth, the first level of props is installed at $1 \mathrm{~m}$ below the ground surface.

g) Step 6: Repeat step 6 to excavate the next stages and install props until the last stage of excavation (i.e., $\mathrm{He}=12 \mathrm{~m}$ ) is completed.

\section{Interpretation of computed results}

\subsection{Development of ground surface settlement}

Fig. 3(a), (b), (c) and (d) illustrate the development of ground surface settlement during different excavation stages in sand with different relative density of 30\%, 50\%, $70 \%$ and $90 \%$, respectively. For each figure, the different excavation stages (h) are taken as $2,5,8,11,14,17,20,23$ and $25 \mathrm{~m}$ (i.e. h/He= $0.08,0.20,0.32,0.44,0.56,0.68,0.80,0.92$ and 1.00). The horizontal and vertical axes of the figures show distance behind the diaphragm wall and ground surface settlement, respectively. It can be seen from the figure that ground surface settlement trough begin to develop as excavation was carried out. This is because of excavation-induced stress release in the retaining ground behind diaphragm wall. The stress release due to excavation subsurface ground movement which resulted in the development of the surface trough (discussed in section 3.5). Moreover, as excavation depth goes deeper, the surface settlement increases and becomes wider. The reason is the degradation of stiffness of sand with strain due to 
excavation-induced stress release. In this study, the ground (sand) is modelled using an advanced constitutive soil model (i.e. hypoplastic model) which is capable to capture small-strain stiffness. The deeper excavation depth induced large shear strain causing significant of stiffness degradation near the diaphragm wall. Consequently, the surface trough is narrower and deeper. The maximum settlement occurred at $2.2 \mathrm{~m}$ away from the diaphragm wall.

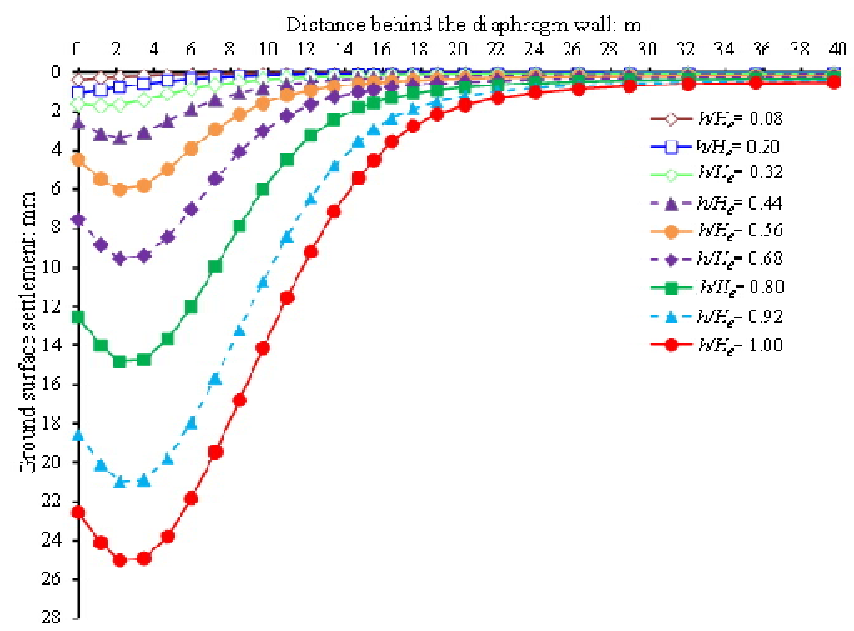

(a)

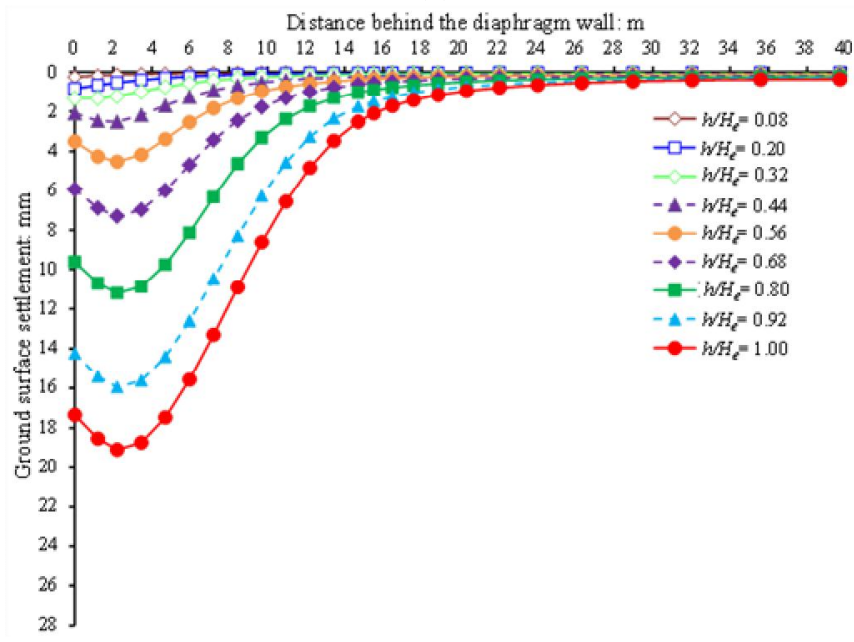

(b)

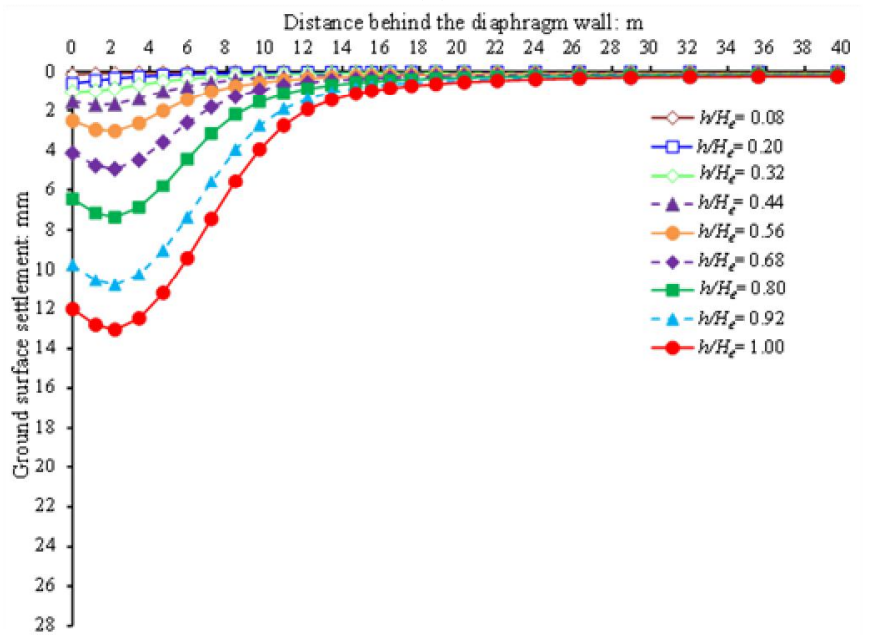

(c)

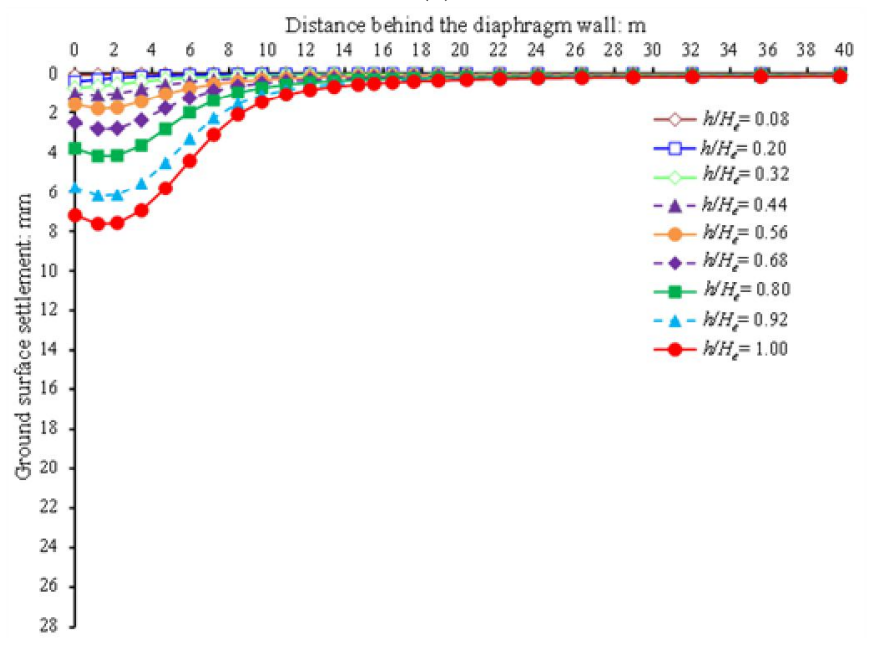

(d)

Figure 2: Ground surface settlement at different excavation (a) $D_{r}=30 \%$; (b) $D_{r}=50 \%$; (c) $D_{r}=70 \%$ and (d) $D_{r}=90 \%$

This is because of friction between the soil and the diaphragm wall. The frictional resistance stop soil particle which are directly in contact with the diaphragm wall. The maximum settlement of magnitude $25 \mathrm{~mm}$ occurred $2.2 \mathrm{~m}$ away from the diaphragm wall when excavation is carried out in the ground (sand) of relative density $\left(D_{r}\right)$ of $30 \%$. This suggests that special precautions should be taken if an excavation is carried adjacent to an existing building/structure. The maximum settlement decreased substantially when the excavation is carried out in the sand with higher relative density. This is because of reason that sand with higher relative density possesses higher stiffness. Though the stress release in dense ground is larger than that of loose ground due to large unit weight of sand with higher relative density, the ground settlement is smaller in dense ground. The higher stiffness of the ground governs the smaller surface settlement. As compared to the excavation-induced maximum settlement in loose sand $\left(D_{r}=30 \%\right)$, the maximum settlement decreased by $24 \%, 48 \%$ and $70 \%$ in the sand of $D_{r}=50 \%, D_{r}=70 \%$ and $D_{r}$ $=90 \%$, respectively.

\subsection{Lateral movement of diaphragm wall due to excavations}

Fig. 4 shows the lateral movement of the diaphragm wall on completion of the excavation in the ground with different relative density (i.e. $D_{r}=30 \%, 50 \%, 70 \%$ and $90 \%$ ). The horizontal and vertical axes represent the lateral wall movement and depth of the diaphragm wall, respectively. The lateral movement is taken as positive if the diaphragm wall movement is towards the excavation. It can be seen from the figure the positive lateral movement increases up to depth of $21.5 \mathrm{~m}$ when the excavation is carried out in sand with $D_{r}=30 \%$. This is because of excavation-induced stress release inside the excavation zone. Consequently, the soil not only settled (see Fig. 3) but also moves laterally towards excavation. As result of the ground movement towards excavation, the 
lateral movement was induced in the diaphragm wall causing bulging of the wall. The depth of the maximum settlement decreases as the sand become denser. This is because of higher stiffness of dense sand. The maximum lateral wall movement was computed as $23,18,13$ and $9 \mathrm{~mm}$ in sand with $D_{r}=30 \%$, $50 \%, 70 \%$ and $90 \%$, respectively. Since the excavation simulated is a multipropped excavation, axial load induced in props installed at different levels (discussed in section 3.3) due to lateral movement wall. It can be observed that the diaphragm wall also moves laterally towards excavation. This implies that the diaphragm wall had translation movement towards excavation. The lateral movement at the toe of the wall is smaller than that near the formation level. The wall in loose ground is larger than that in denser ground. The reason is the stiffness of the sand which is higher for dense sand and smaller for loose sand. The maximum toe movement of diaphragm wall in lateral direction was as 5, 3,2 and $1 \mathrm{~mm}$ in sand with $D_{r}=30 \%, 50 \%, 70 \%$ and $90 \%$, respectively.

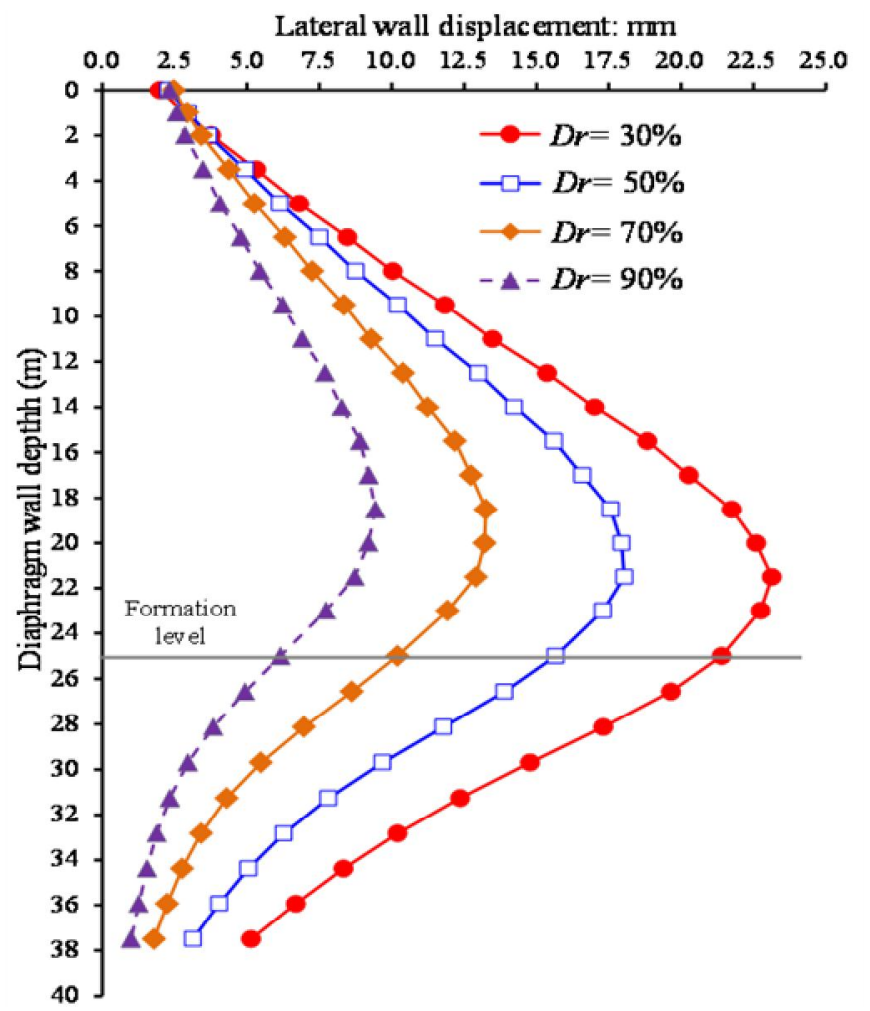

Figure 4: Wall deflection on completion of excavation

\subsection{Development of prop loads due to excavation}

As discussed, axial load is induced in props during excavation due to lateral wall movement. The induced axial loads at each level and in different ground conditions were compared. Fig. 5 shows induced load in each prop at eight different levels (i.e. Prop 1, Prop 2, Prop 3, Prop 4, Prop 5, Prop 6, Prop 7 and Prop 8 ) on completion of excavation in sand with different relative density (i.e. $D_{r}=30 \%, 50 \%, 70 \%$ and $90 \%$ ). It can be observed from the figure that the prop loads profile is similar for excavation in sand with different relative density. The prop load increases from Prop 1 to Prop 6. However, the induced load decreases in the props installed lower than Prop 6 (i.e. Prop 7 and Prop 8). The load increment is consistent with the diaphragm wall deflection profile (see Fig. 4). This is because the wall lateral movement increases along the depth after completion of excavation. The installed prop support the diaphragm wall by generating the axial force. The ground moves laterally towards the excavation due to stress-release resulting in pushing of the wall. Consequently, the wall deflected laterally causing the development of load in props. Moreover, it can observed that the prop load at each level decrease when the excavation is carried out in dense sand. This observation is also consistent with the diaphragm wall profile. The reason behind the reduction of the load in denser ground is stiffness of the sand. With relative density increment, the stiffness of sand increased significantly. Consequently, the lateral movement of the diaphragm wall move smaller than in looser sand. As result, the load developed at each prop level (i.e. from Prop 1 to Prop 8) in denser sand is less than that in loose sand. The prop load generated in the densest sand $\left(D_{r}=90 \%\right)$ is $23 \%$ smaller than that in the loosest $\left(D_{r}=30 \%\right)$. The induced load in props supports the diaphragm wall and keeps the in equilibrium. Hence the diaphragm remains stable on completion of the excavation. Therefore, it is necessary for a geotechnical engineer to proper design the props which can sustain the load generated in the props. The improper design may lead to collapse of the diaphragm wall and can be vulnerable for adjacent buildings/structures.

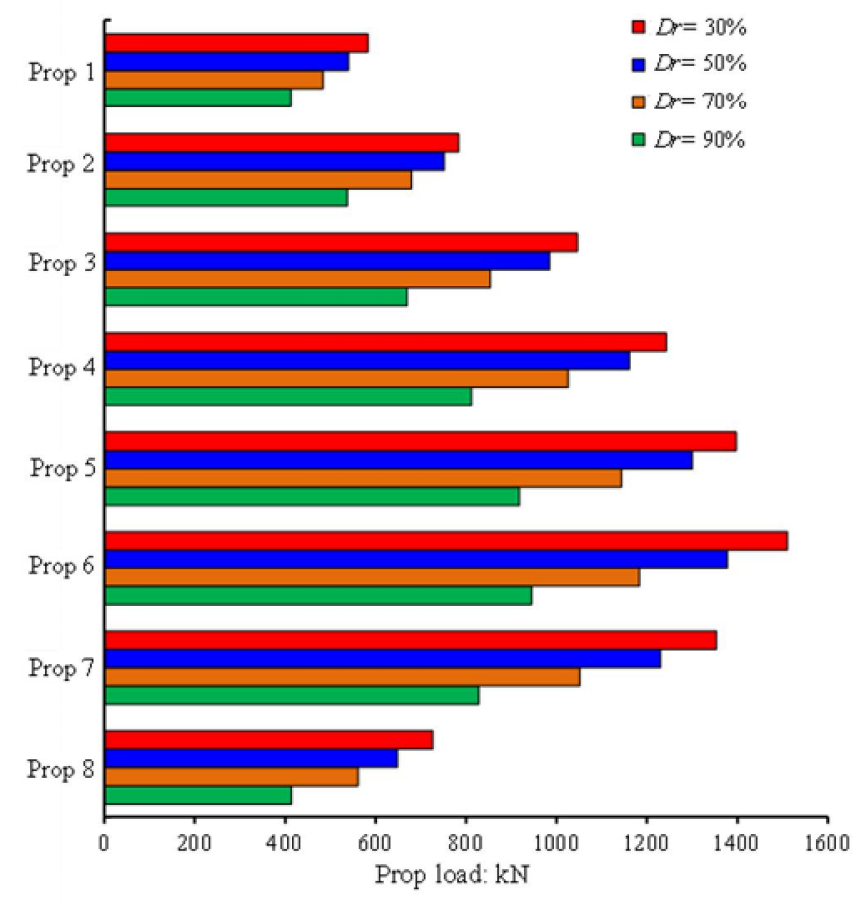

Figure 5: Induced prop load after excavation 
Dildar Ali Mangnejo et al., International Journal of Emerging Trends in Engineering Research, 9(6), June 2021, 741 - 747

\section{Conclusions}

A detailed parametric analysis of the ground deformation mechanism due to excavation with different depths in sand with different densities $\left(D_{r}=30 \%, 50 \%, 70 \%\right.$ and $\left.90 \%\right)$ is presented. 3D finite element analyses were carried out using a hypoplastic model, which considers strain-dependent and path-dependent soil stiffness. Based on the ground conditions, geometries and excavation method modelled, the following conclusions can be drawn.

(a) The maximum settlement decreased substantially when the excavation is carried out in the sand with higher relative density. This is because of reason that sand with higher relative density possesses higher stiffness. Though the stress release in dense ground is larger than that of loose ground due to large unit weight of sand with higher relative density, the ground settlement is smaller in dense ground. The higher stiffness of the ground governs the smaller surface settlement.

(b) As compared to the excavation-induced maximum settlement in loose sand $\left(D_{r}=30 \%\right)$, the maximum settlement decreased by $24 \%, 48 \%$ and $70 \%$ in the sand of $D_{r}=50 \%, D_{r}=70 \%$ and $D_{r}=90 \%$, respectively.

(c) The lateral movement increases up to depth of $21.5 \mathrm{~m}$ on completion of the excavation in sand with $D_{r}=30 \%$. This is because of excavation-induced stress release inside the excavation zone. The depth of the maximum settlement of the wall decreases as the sand become denser. This is because of higher stiffness of dense sand. The maximum lateral wall movement was computed as $23,18,13$ and 9 $\mathrm{mm}$ in sand with $D_{r}=30 \%, 50 \%, 70 \%$ and $90 \%$, respectively.

(d) The prop load increases from Prop 1 to Prop 6. However, the induced load decreases in the props installed lower than Prop 6 (i.e. Prop 7 and Prop 8). This is because the wall lateral movement increases along the depth after completion of excavation. The prop load at each level decrease when the excavation is carried out in dense sand. The reason behind the reduction of the load in denser ground is stiffness of the sand. With relative density increment, the stiffness of sand increased significantly.

\section{REFERENCES}

[1] Atkinson JH, Richardson D, Stallebrass SE. Effect of recent stress history on the stiffness of over consolidated soil. Géotechnique, 1990; 40(4):531-540.

[2] Atkinson JH, Sällfors G. Experimental determination of stress-strain-time characteristics in laboratory and in-situ tests. General report. In Proceedings of 10th European Conference on Soil Mechanics and Foundation Engineering, Florence, Italy, 1991:Vol.3, pp. 915-956

[3] Dinakar KN, Prasad SK. Behaviour of tie back sheet pile wall for deep excavation using plaxis. International Journal of Research in Engineering and Technology,
2014 03(18):97-103

[4] Gudehus G. A comprehensive constitutive equation for granular materials. Soils and Foundations, 1996;36, No. $1,1-12$.

[5] Gudehus G, Mašín D. Graphical representation of constitutive equations. Géotechnique, 2009; 59, No. 2, 147-151, http://dx.doi.org/10.1680/geot.2007.00155.

[6] Herle I, Gudehus G. Determination of parameters of a hypoplastic constitutive model from properties of grain assemblies. Mech. Cohesive Frictional Mater. 1999; 4, No. 5, 461-486

[7] Hibbitt, Karlsson, Sorensen. Abaqus user's manual, version 6.8.2. Providence, RI, USA: Hibbitt, Karlsson\& Sorensen Inc; 2008.

[8] Hsieh, P.G. and Ou, C.Y. (2016). "Simplified approach to estimate the maximum wall deflection for deep excavations with cross walls in clay under the undrained condition." ActaGeotechnica, 11(1), 177-189.

[9] Hsieh, P.G., Ou, C.Y., and Hsieh, W.H. (2016). "Efficiency of excavations with buttress walls in reducing the deflection of the diaphragm wall." ActaGeotechnica, 11(5), 1087-1102.

[10]Hsieh, P.G., Ou, C.Y., and Lin, Y.L. (2012). "Three-dimensional numerical analysis of deep excavations with cross walls." ActaGeotechnica, 8, 33-48.

[11] Hsiung BCB. A case study on the behaviour of a deep excavation in sand. ComputGeotech 2009;36:665-75.

[12] Hsiung, BCB., Yang, K.H., Aila, W., and Hung, C. (2016). "Three-dimensional effects of a deep excavation on wall deflections in loose to medium dense sands." Computers and Geotechnics, 80, 138-151.

[13] Hsiung BCB. Observations of the ground and structural behaviours induced by a deep excavation in loose sands. ActaGeotechnica. 2020 Jun;15(6):1577-93.

[14] Hsiung BCB, Yang KH, Aila W, Ge L. Evaluation of the wall deflections of a deep excavation in Central Jakarta using three-dimensional modeling. Tunnelling and Underground Space Technology. 2018 Feb 1;72:84-96.

[15] Hong Y, Ng CW. Base stability of multi-propped excavations in soft clay subjected to hydraulic uplift. Canadian Geotechnical Journal. 2013;50(2):153-64.

[16] Hong $\mathrm{Y}, \mathrm{Ng} \mathrm{CW}$, Wang LZ. Initiation and failure mechanism of base instability of excavations in clay triggered by hydraulic uplift. Canadian Geotechnical Journal. 2015;52(5):599-608.

[17]Hong Y, Koo RC, Zhou C, Ng CWW, Wang LZ. Small strain path-dependent stiffness of Toyoura sand: laboratory measurement and numerical implementation. International Journal of Geomachanics; 2016;17(1):110.

[18] Ishihara K. Liquefaction and flow failure during earthquakes. Géotechnique. 1993; 43(3), 351-415.

[19] Jáky J. The coefficient of earth pressure at rest. J. Soc. of Hungarian Arch. AndEngrs, 1944; 355-358 (in 
Dildar Ali Mangnejo et al., International Journal of Emerging Trends in Engineering Research, 9(6), June 2021, 741 - 747

Hungarian).

[20] Korff M, Mair, RJ, Van Tol, FAF. Pile-Soil Interaction and Settlement Effects Induced by Deep Excavations. Journal of Geotechnical and Geoenvironmental Engineering, 2016; 142(8), 04016034.

[21]Liyanapathirana DS, Nishanthan R. Influence of deep excavation induced ground movements on adjacent piles. Tunnelling and Underground Space Technology; 2016;5 2:168-81.

[22] Maeda K, Miura K. Relative density of dependency of mechanical properties of sands. Soils Found, 1999; 39(1):69-79.

[23] Niemunis A, Herle I. Hypoplastic model for cohesionless soils with elastic strain range. Mech. Cohesive-Frict. Mater, 1997; 2: 279-299 